\title{
Quality by Design (QbD) Approach for Optimization and Characterization of Micro emulsion based Nasal formulation of Antipsychotic/Antischizophrenic Drug- Aripiprazole
}

\author{
Sharada L Deore1,*, Bhushan A Baviskar ${ }^{1}$, Anjali Kide ${ }^{1}$, Ashwin D Deshmukh ${ }^{1}$, Yogita B Khandare ${ }^{1}$, Ramdas B Rode $^{2}$ \\ 'Government College of Pharmacy, Amravati, Maharashtra, INDIA. \\ 2S.M.B.T. College of Pharmacy, Dhamangaon, Nashik, Maharashtra, INDIA.
}

\begin{abstract}
Introduction: Present study is focused to develop micro emulsion based nasal formulation of poorly water soluble antipsychotic/anti-schizophrenic drug Aripiprazole. Materials and Methods: Different surfactants and co surfactants are screened by implementing pseudo ternary phase diagram. Effect of concentrations of four independent variables- oil (X1), Surfactant $(X 2)$, co-surfactant $(X 3)$ and water $(X 4)$ on two dependent variablesparticle size (Y1) and drug content (Y2) is studied from surface response plots obtained by application of Box Behnken Design Experiment. QTPP and CQA mediated risk assessment applied to ensure desirable quality, safety and efficacy of developed microemulsion. Developed microemulsion evaluated for appearance, particle size, viscosity, drug content, pH, conductivity, drug release, zeta potential, polydispersity index, nasal toxicity and stability. Results: DoE based OBD approach lead development of suitable optimized batch of Aripiprazole micro emulsion with particle size $95.2 \mathrm{~nm}$, viscosity $120 \mathrm{cp}, \mathrm{pH} 6.0,90 \%$, drug content and about $87.33 \%$ nasal permeability release within $4 \mathrm{hr}$. Risk assessment
\end{abstract}

helped in identifying identification robust design parameters for rapid development of stable aripiprazole micro emulsion. The critical quality attributes (CQAs) like solubility and compatibility with excipients, dosage form, particle size, turbidity, drug content and drug release have greater impact on the stability and therapeutic performance of micro emulsion of aripiprazole. Conclusion: Aripiprazole containing intranasal micro emulsion is successfully developed by quality by design approach for understanding the critical quality attributes and microemulsion is better alternative over conventional delivery systems.

Key words: Aripiprazole, Micro emulsion, Intranasal, QBD, OTPP, CQA.

Correspondence

Dr. Sharada L Deore

Government College of Pharmacy, Kathora Naka, Amravati-444 604, Maharashtra, INDIA.

Email: sharudeore_2@yahoo.com

DOI: 10.5330/ijpi.2020.3.52

\section{INTRODUCTION}

Aripiprazole is an atypical antipsychotic drug with chemical name 7-[4-[4-(2,3-dichlorophenyl)-1-piperazinyl]butoxy]-3,4-dihydro-2(1H) quinolinone. ${ }^{1}$ It belongs to the chemical class of benzisoxazole derivatives and is indicated for the management of schizophrenia. Study revealed that Aripiprazole have high affinity towards D2, D3 - Dopamine and 5 $\mathrm{HT}_{7}$ serotonin receptors. ${ }^{2}$ However, the exact root cause of Schizophrenia is still unclear, Aripiprazole have shown significant improvement in Positive and negative symptoms in schizophrenic patients which indirectly suggests that dopamine and serotonin agonists helps in management of schizophrenia by restoring dopamine level in frontal cortex region of brain. ${ }^{2}$ Based on the extremely low hydrophobicity $(<1$ $\mu \mathrm{g} / \mathrm{mL}$ at room temperature) and lipophilicity, it is classified as a class IV compound according to Biopharmaceutical Classification System (BCS). It is also found that due to poor solubility drug accumulates in body by $99 \%$ binding with plasma protein. ${ }^{3}$ If the solubility of Aripiprazole is enhanced, it can reduce dose frequency as well as drug deposition; also enhance bioavailability of drug at targeted site. ${ }^{3}$

Micro emulsion technique offers a promising solution for solubilisation of such drugs during formulation. ${ }^{4}$ Intranasal route is one of the advanced approaches to deliver antipsychotic or neuroprotective drug directly to brain via olfactory and trigeminal nerves through cavity by avoiding blood brain barrier hurdle. ${ }^{5} \mathrm{QBD}$ is now an integral part of formulation development at lab as well as industrial level because factorial design gives best optimized batch for pilot plant scale up. ${ }^{6,7}$
Present work is focused on QBD approach based development of effective intranasal drug delivery system for Aripiprazole in the form of micro emulsion.

\section{MATERIALS AND METHODS}

\section{Materials}

Gift sample of Aripirazole was provided by Alembic Pharmaceuticals, Vadodara. The organic solvents, excipients and other chemicals of analytical grade were procured from S.D Fine chemicals Pvt. Ltd. Mumbai, India. Design of Experiment (DOE), Version 7 was used for assessment of design to study optimization. Prosim software was used for constructing pseudo ternary diagram.

\section{Methods \\ Solubility Studies}

To select the best oil/surfactant/co surfactant for preparation of micro emulsion, saturated solubility studies were carried out in different oils/ surfactants/co surfactants. ${ }^{8}$ Excess amount of Aripiprazole was added to $200 \mathrm{mg}$ of each oil/surfactant/co surfactant in glass vial. Mixtures were solicited in solicitor for $30 \mathrm{~min}$. Mixture containing vials were kept in orbital shaker for $72 \mathrm{hr}$ to form homogenous mixture. Samples were centrifuged at $3000 \mathrm{rpm}$ for $15 \mathrm{~min}$. from supernatant liquid $0.1 \mathrm{ml}$ of solution was pipette out and diluted with ethanol. Samples were analyzed 
by UV-Spectrometric at $255 \mathrm{~nm}$ wavelength against blank sample (same concentration of oil without drug) and calculated solubility of Aripiprazole.

\section{Pseudo Ternary Phase Diagram}

The pseudo ternary phase diagrams were developed by the water titration method. ${ }^{8}$ Aliquots of each surfactant and co surfactant mixture $\left(\mathrm{S}_{\text {mix }}\right)$ were mixed with the oil at ambient temperature in a $(2: 1,1: 2,1: 1)$ ratio. For each phase diagram, the ratio of oil to the $S_{\text {mix }}$ was varied as $9: 1$, $8: 2,7: 3,6: 4,5: 5,4: 6,3: 7,2: 8,1: 9(\mathrm{v} / \mathrm{v})$. Water was added drop wise to each oil- $\mathrm{S}_{\text {mix }}$ mixture under vigorous stirring. After equilibrium, the samples were visually checked and determined as being clear micro emulsions. No heating was done during the preparation. Phase diagrams (Figure 1) were constructed using prosim software.

\section{Formulation of Micro emulsion}

The trial batches of micro emulsion were prepared by phase titration method. ${ }^{9}$ Initially required quantity of Aripiprazole was dissolved in appropriate quantity of oil. The mixture was homogenized and to it, accurately weighed quantity of surfactant: co surfactant blends were added in small portion with constant stirring. The blends were mixed thoroughly using magnetic stirrer and to it drop wise double distilled water added with continuous stirring.

\section{Optimization of Micro emulsion formulation}

Optimization of micro emulsion formulation was explored by applying response surface methodology and experimental design BBD (Box Behnken Design) using 3 level factorial designs. ${ }^{10-12}$ Polynomial model was constructed for optimization of Aripiprazole keeping four independent and two dependent variables [Table 1] using Design Expert (version 7.1, Stat-Ease Inc, Minneapolis, Minnesota) and analyzed statistically by analysis of variance (ANOVA).

\begin{tabular}{cccc|}
\hline Independent variable & Low level & Medium level & High level \\
\hline Oleic acid(X1) & 5 & 10 & 15 \\
Tween $\mathbf{8 0}(\mathbf{X} 2)$ & 12 & 25.931 & 36 \\
Transcutol-p(X3) & 24.5 & 47.5 & 73.5 \\
Water (X4) & 8 & 16 & 24 \\
Dependent Variable - Y1 & Particle Size, Y2 = Drug Content \\
\hline
\end{tabular}

Further optimization of formulation was done by Design Expert software. 29 experiments were planned as per $3^{4}$ factorial designs. Particle size and drug content was selected as a response for optimization.

\section{Quality Target Product Profile (QTPP) and Critical Quality Analysis (CQA)}

Description of the target product profile for identity, dosage form, strength, route of administration, appearance, content uniformity, pharmacokinetics, bioequivalence, assay etc is called as QTPP. CQAs are usually defined properties like physicochemical and biological parameters which affect the performance of the product. Identification of QTPP and CQA based on drug, excipient, manufacturing factors and packaging system is performed. Developed QTPP and identified critical attributes responsible for desired quality, safety, efficacy of AME are summarised in Table 2 which will surely helpful in stable micro emulsion development. ${ }^{10-14}$

\section{Pharmaceutical evaluation of Micro emulsion}

Optical clarity (Percentage transmittance): Percentage transmittance of each formulation was measured at $650 \mathrm{~nm}$ using UV-spectrophotometer against distilled water as blank. ${ }^{9,15}$ Percentage transmittance indicates the homogenous nature and clarity of formulation.

Globule size determination: The globule size was determined using photon correlation spectroscopy (PCS) with in-built Zetasizer). The instrument is based on the principle of dynamic light scattering (DLS). The technique measures particle diffusion due to Brownian motion and relates this to the size of the particles. The particle size is then calculated from the translational diffusion coefficient using the Strokes-Einstein equation. ${ }^{16}$

Table 1: Observed responses based on Box Behnken Design.

\begin{tabular}{|c|c|c|c|c|c|c|}
\hline Code & $\begin{array}{l}\text { Oil } \\
(\mathrm{X} 1)\end{array}$ & $\begin{array}{c}\text { Surfactant } \\
\text { (X2) }\end{array}$ & $\begin{array}{c}\text { Co- } \\
\text { surfactant } \\
\text { (X3) }\end{array}$ & Water & $\begin{array}{c}\text { Particle } \\
\text { size } \\
\text { (R1) }\end{array}$ & $\begin{array}{c}\text { Drug } \\
\text { Content } \\
(\%)\end{array}$ \\
\hline $\mathrm{F} 1$ & 10 & 17 & 47.225 & 24 & 214 & 85.5 \\
\hline F2 & 10 & 26 & 47.25 & 16 & 411 & 50 \\
\hline F3 & 5 & 26 & 47.25 & 8 & 792 & 39 \\
\hline F4 & 10 & 24 & 34.5 & 24 & 130 & 83.33 \\
\hline F5 & 15 & 26 & 47.25 & 8 & 250 & 56.67 \\
\hline F6 & 10 & 17 & 34.5 & 16 & 256 & 90 \\
\hline F7 & 10 & 17 & 47.5 & 8 & 300 & 43.33 \\
\hline F8 & 10 & 26 & 60 & 24 & 977 & 60 \\
\hline F9 & 5 & 17 & 34.05 & 16 & 95.2 & 95 \\
\hline F10 & 10 & 26 & 34.5 & 16 & 218 & 83.56 \\
\hline F11 & 10 & 26 & 47.25 & 18 & 614 & 56.66 \\
\hline F12 & 10 & 26 & 47.25 & 16 & 227 & 75 \\
\hline $\mathrm{F} 13$ & 10 & 35 & 47.25 & 8 & 442 & 92 \\
\hline F14 & 15 & 26 & 34.5 & 16 & 665 & 71 \\
\hline F15 & 10 & 35 & 60 & 16 & 450 & 77.23 \\
\hline F16 & 15 & 26 & 47.25 & 24 & 218 & 23.88 \\
\hline F17 & 10 & 35 & 34.5 & 16 & 660 & 95 \\
\hline F18 & 5 & 26 & 47.25 & 24 & 178 & 77 \\
\hline F19 & 15 & 17 & 47.25 & 16 & 392 & 58.34 \\
\hline F20 & 10 & 35 & 47.25 & 24 & 509 & 50.05 \\
\hline $\mathrm{F} 21$ & 15 & 26 & 60 & 16 & 302 & 75 \\
\hline $\mathrm{F} 22$ & 5 & 17 & 47.25 & 16 & 130 & 70.45 \\
\hline $\mathrm{F} 23$ & 5 & 26 & 60 & 8 & 166 & 71.66 \\
\hline F24 & 10 & 26 & 60 & 16 & 673 & 75.45 \\
\hline F25 & 10 & 26 & 47.25 & 16 & 614 & 56.67 \\
\hline F26 & 5 & 35 & 47.25 & 16 & 227 & 77.33 \\
\hline F27 & 10 & 17 & 60 & 16 & 561 & 39 \\
\hline F28 & 10 & 26 & 47.25 & 8 & 250 & 71.66 \\
\hline F29 & 5 & 26 & 47.25 & 16 & 1209 & 43.33 \\
\hline
\end{tabular}




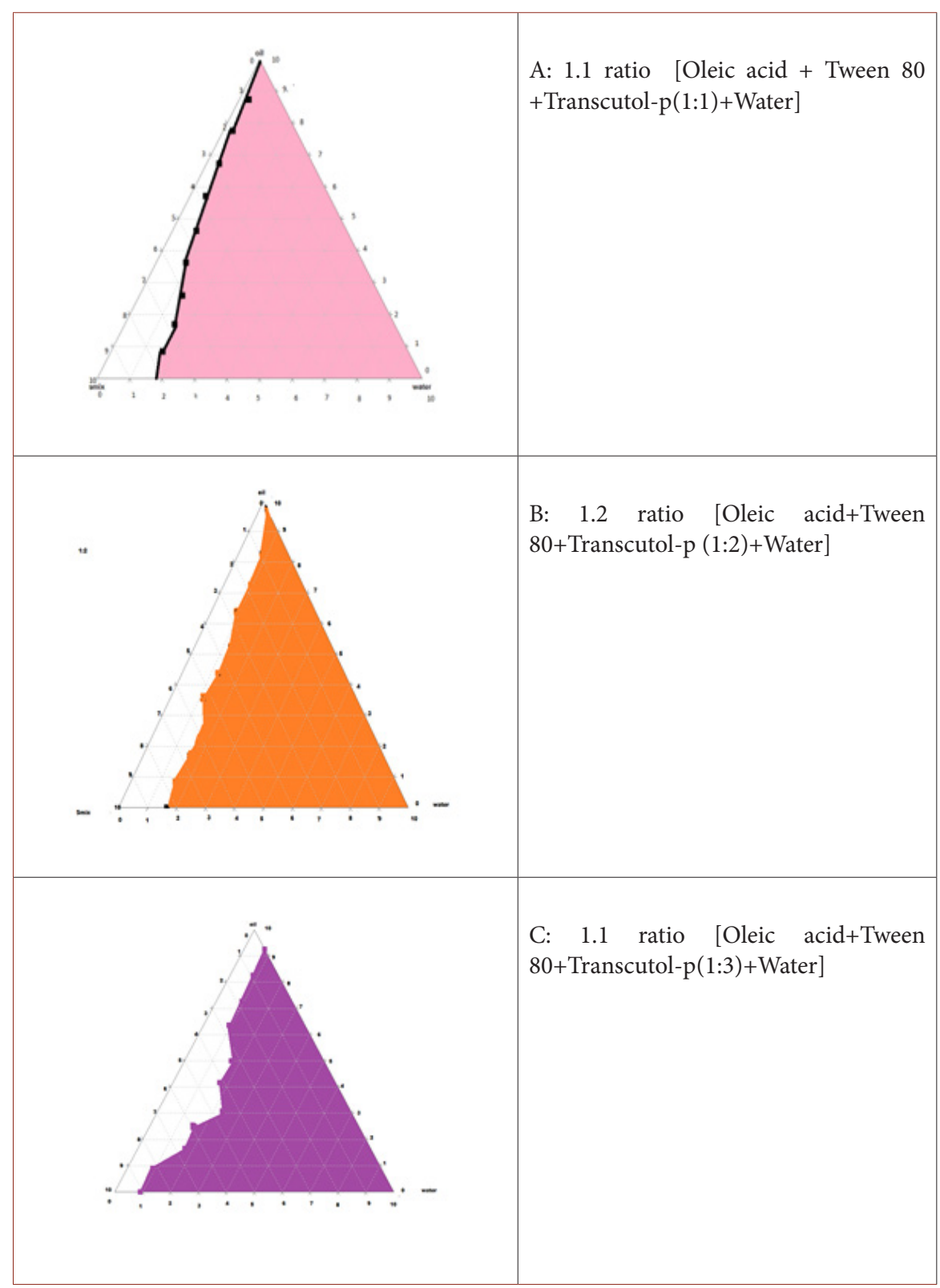

Figure 1: Pseudoternary phase diagrams of various ratio combinations.

Zeta potential: Malvern zetasizer Nano was used to measure the zeta potential of the globules based on the electrophoresis and electrical conductivity of the formed micro emulsion. The electrophoresis mobility $(\mathrm{mm} / \mathrm{s})$ of the particles was converted to the zeta potential by in-built software. Measurements were performed using small volume disposable zeta cell. ${ }^{16,17}$

Viscosity: Viscosity of the formulations were determined using Brookfield cone and plate Rheometer using CPE spindle at the rotational speed of $5 \mathrm{rpm}$, shear rate of 10 at $33.8 \pm 0.3^{\circ} \mathrm{C} . .^{14,15}$

pH measurement: The excipients used in the formulation decide the $\mathrm{pH}$ of the final preparation. $\mathrm{pH}$ is also responsible for stability of micro emulsion. The $\mathrm{pH}$ value of $\mathrm{ME}$ was determined using digital $\mathrm{pH}$ meter (Equip-Tronics, EQ-610), standardized using $\mathrm{pH} 4$ and 7 buffers. ${ }^{16}$

Refractive Index: The refractive index of the system was measured by a simple Abbe's refractometer by placing 1 drop of AME on the slide. ${ }^{14,15}$

Drug content Estimation: Micro emulsion equivalent to $15 \mathrm{mg}$ of Aripiprazole was dissolved in suitable quantity of ethanol $(100 \mathrm{ml})$.
The samples were mixed thoroughly to dissolve the drug in ethanol and percentage drug content analysed using Shimadzu UV visible spectrophotometer at $255 \mathrm{~nm} \cdot{ }^{12-14}$

Biological Evaluation: Freshly excised sheep nasal mucosa without septum part was obtained from the slaughter house. This membrane was kept in PBS at pH 6.4 for 15 min to equilibrate. The superior nasal concha of thickness about $0.2 \pm 0.5 \mathrm{~mm}$ was identified and separated from the nasal membrane. The excised superior nasal membrane was then mounted on a Franz diffusion cell. The tissue was stabilized using phosphate buffer $\mathrm{pH} 6.0$ in both the compartments and allowed to stir for $15 \mathrm{~min}$ on a magnetic stirrer with Teflon coated magnetic bar and allow stirring such that the nasal membrane flushes the diffusion fluid. After $15 \mathrm{~min}$, solution from both the compartments was removed and fresh phosphate buffer $\mathrm{pH}$. 6.0 were filled in the receptor compartment. The mounting of the nasal membrane was done using glue at the brim of the donor compartment to avoid leakage of the test sample and supported with rubber crossing over the cell. Samples from the receptor 
Table 2: Analysis of variance (ANOVA) results for Particle Size (R1) and Drug Content (R2).

\begin{tabular}{|c|c|c|c|c|c|c|}
\hline \multicolumn{7}{|c|}{ Analysis of variance results for Particle Size (R1) } \\
\hline Source & Sum of Squares & $d_{f}$ & Mean Square & FValue & $p$-value Prob $>F$ & Remark \\
\hline Model & $5.33 \mathrm{E}+05$ & 3 & $1.78 \mathrm{E}+05$ & 5.08 & 0.007 & Significant \\
\hline $\mathrm{AC}$ & $1.75 \mathrm{E}+05$ & 1 & $1.75 \mathrm{E}+05$ & 5 & 0.0346 & Significant \\
\hline $\mathrm{CD}$ & $3.80 \mathrm{E}+05$ & 1 & $3.80 \mathrm{E}+05$ & 10.86 & 0.0029 & Significant \\
\hline $\mathrm{A}^{\wedge} 2$ & $1.80 \mathrm{E}+05$ & 1 & $1.80 \mathrm{E}+05$ & 5.15 & 0.0322 & Significant \\
\hline Residual & $8.75 \mathrm{E}+05$ & 25 & 35004.81 & & & \\
\hline Lack of Fit & $8.00 \mathrm{E}+05$ & 22 & 36371.37 & 1.46 & 0.4304 & not significant \\
\hline Pure Error & 74950.27 & 3 & 24983.42 & & & \\
\hline Cor Total & $1.41 \mathrm{E}+06$ & 28 & & & & \\
\hline \multicolumn{7}{|c|}{ Analysis of variance results for Drug Content (R2) } \\
\hline Source & Sum of Squares & $\mathrm{d}_{f}$ & Mean Square & F Value & p-value Prob $>$ F & Remarks \\
\hline Model & 9524.83 & 14 & 680.34 & 2.64 & 0.0399 & Significant \\
\hline A-oil & 269.27 & 1 & 269.27 & 1.04 & 0.324 & NS \\
\hline B-surfactant & 269.26 & 1 & 269.26 & 1.04 & 0.324 & NS \\
\hline C-co surfactant & 246.8 & 1 & 246.8 & 0.96 & 0.3444 & NS \\
\hline D-water & 104.21 & 1 & 104.21 & 0.4 & 0.5351 & NS \\
\hline $\mathrm{AB}$ & 285.27 & 1 & 285.27 & 1.11 & 0.3105 & NS \\
\hline $\mathrm{AC}$ & 1.02 & 1 & 1.02 & $3.97 \mathrm{E}-03$ & 0.9507 & NS \\
\hline $\mathrm{AD}$ & 1561.23 & 1 & 1561.23 & 6.06 & 0.0274 & Significant \\
\hline $\mathrm{BC}$ & 240.86 & 1 & 240.86 & 0.93 & 0.35 & NS \\
\hline $\mathrm{BD}$ & 1530.04 & 1 & 1530.04 & 5.94 & 0.0288 & Significant \\
\hline $\mathrm{CD}$ & 560.03 & 1 & 560.03 & 2.17 & 0.1626 & NS \\
\hline$A^{\wedge} 2$ & 29.38 & 1 & 29.38 & 0.11 & 0.7406 & NS \\
\hline $\mathrm{B}^{\wedge} 2$ & 650.99 & 1 & 650.99 & 2.53 & 0.1343 & NS \\
\hline$C^{\wedge} 2$ & 1495.21 & 1 & 1495.21 & 5.8 & 0.0303 & Significant \\
\hline $\mathrm{D}^{\wedge} 2$ & 374.18 & 1 & 374.18 & 1.45 & 0.2482 & NS \\
\hline Residual & 3607.55 & 14 & 257.68 & & & \\
\hline Lack of Fit & 2919.98 & 11 & 265.45 & 1.16 & 0.5112 & NS \\
\hline Pure Error & 687.57 & 3 & 229.19 & & & \\
\hline Cor Total & 13132.37 & 28 & & & & \\
\hline
\end{tabular}

compartment were withdrawn at predetermined time intervals and analysed using the UV-spectrophotometer method at $280 \mathrm{~nm}$. Each sample removed was replaced by an equal volume of diffusion media. ${ }^{15-17}$

Stability studies: The optimized formulations were subjected to physical stability $^{8,9}$ testing for periods of 3 months at room temperature to study patient usage conditions. After 3 months of storage in Refrigerator condition $\left(4^{\circ} \mathrm{C}\right)$, the formulations were examined periodically after 1,2 and 3 months for physical stability by means of creaming, phase separation, or flocculation, accelerated centrifugation cycle $(3000 \times \mathrm{g}$ for $15 \mathrm{~min}$ ). The optimized formulations were subjected to chemical stability by means of drug content, $\mathrm{pH}$, Viscosity. Thermodynamic stability ${ }^{9-11}$ studies included the exposure of prepared Micro emulsion to thermal (both low and high) as well as mechanical stress to study effect on homogeneity of Micro emulsion. The tests were carried out in two part- a. Freeze-Thaw Cycles (FTC): AME stored at $25^{\circ} \mathrm{C}$ for $24 \mathrm{~h}$ and followed by $24 \mathrm{~h}$ at $-5^{\circ} \mathrm{C}$, the cycle is repeated three times and change is noted. b. Centrifugations test: Centrifugation of formulations for $30 \mathrm{~min}$ at $3500 \mathrm{rpm}$.

\section{RESULTS}

\section{Solubility Studies}

To select the best oil for preparation of micro emulsion formulation, saturated solubility studies were carried out in different oils and analysed by UV spectrophotometer. Aripiprazole has shown highest solubility (concentration $145 \mathrm{mg} / \mathrm{ml}$ ) in oleic acid than other oils. Similarly surfactants and co surfactants were screened for solubility of Aripiprazole and it is found that Aripiprazole shown highest solubility in Tween $80(37.28 \mathrm{mg} / \mathrm{ml})$ and Transcutol-p $(40 \mathrm{mg} / \mathrm{ml})$.

\section{Pseudo Ternary Phase Diagram}

Pseudo ternary phase diagrams were constructed by using Prosim software to determine ranges of oil phase, surfactant and cosurfactant 
composition. The boundary layer of o/w micro-emulsion was determined in each phase diagram. Components used for construction of pseudo ternary phase diagram are Oleic acid (Oil phase), Tween 80 (Surfactant), Transcutol-p (Co-surfactant) and double distilled water. These phase diagrams [Figure 1: A, B, C] were prepared by 1:1,1:2, 1:3 ratio, the ratio surfactant/co surfactant $\left(\mathrm{S}_{\text {mix }}\right)$ were varied as 9:1 to 1:9.

\section{Optimization of Micro emulsion formulation}

$3^{4}$ factorial design based on Box Behnken Experimental design for response surface Methodology was applied for optimization of formulation variables. Oleic acid(X1), Tween 80(X2), Transcutol-p(X3) and Water (X4) were taken as independent variables while Particle size (Y1) and Drug content (Y2) were taken as dependent variables to study 3D response plots [Figure 2]. Effect of independent variables on dependent variables was studied for understanding of drug and $\mathrm{S}_{\text {mix }}$ (Surfactant and co-surfactant) compatibility.

Dependent variables i.e. Responses Particle size (Y1) and Drug Content (Y2) were found between ranges $1209 \mathrm{~nm}$ to $214 \mathrm{~nm}$ and 43.33 to $85.5 \%$ respectively as shown in Table 1. Estimation of quantitative effects of different combinations of factors and factor levels on particle size and drug content were studied by calculating response models with the help of Design Expert Software by applying coded values of factor levels. Responses coded as R1-Particle size and R2-drug content, Final coded equations in terms of factors $\mathrm{R} 1$ and $\mathrm{R} 2$ are as follows:

$\mathrm{Y} 1=456.71-465.99 \mathrm{X}_{1} \mathrm{X}_{3}+637.67 \mathrm{X}_{3} \mathrm{X}_{4}-160.61 \mathrm{X}_{1}^{2}$

$\mathrm{Y} 2=57-5.49 \mathrm{X}_{1}+7.5 \mathrm{X}_{2}-9.81 \mathrm{X}_{3}+3.37 \mathrm{X}_{4}+11.26 \mathrm{X}_{1} \mathrm{X}_{2}-1.16 \mathrm{X}_{1} \mathrm{X}_{3}-17.88$ $\mathrm{X}_{1} \mathrm{X}_{4}+20.04 \mathrm{X}_{2} \mathrm{X}_{3}-26.02 \mathrm{X}_{2} \mathrm{X}_{4}-25.65 \mathrm{X}_{3} \mathrm{X}_{4}+2.21 \mathrm{X}_{1}^{2}+17.82 \mathrm{X}_{2}^{2}+58.26 \mathrm{X}_{3}^{2}$ $-7.59 \mathrm{X}_{4}^{2}$.

From ANOVA study of both responses, it is observed that Quadratic model was best fit model. ANOVA details of both responses are given in Table 2. Terms with positive signs indicates positive effect and negative sign indicates negative effect upon responses.

\section{Quality Target Product Profile (QTPP) and Critical Quality Analysis (CQA)}

Quality target product profile (QTPP) results are shown in Table 2. Raw material QTPP was determined by Preformulation and physicochemical studies. Critical quality attributes (CQAs) for AME and their justification is summarised in Table 2. Packaging attribute and storage and stability attribute (critical analysis) are elaborated in Table 2.

\section{Pharmaceutical evaluation of Micro emulsion}

QBD optimised Batch F9 of micro emulsion formulation was finalised and evaluated for various pharmaceutical parameters. Results of pharmaceutical evaluations obtained are summarised in Table 3. Results of stability studies are elaborated in Table 3 . It was seen that after $4 \mathrm{hr}$ of diffusion, the drug released from the formulation F9 found faster and more than that of the other batches i.e., $91.33 \%$ as shown in Figure 4.

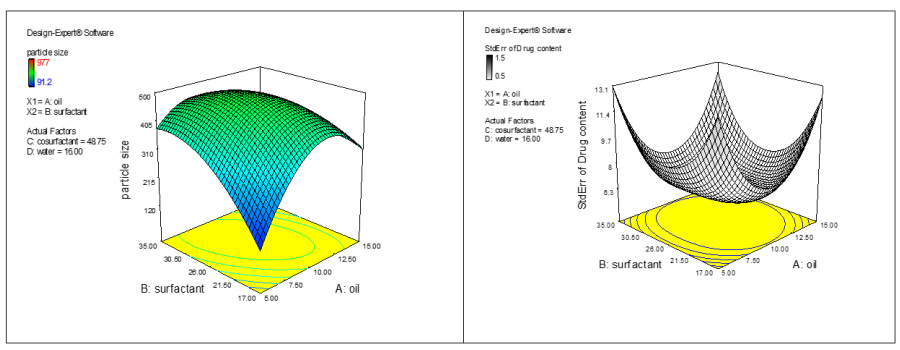

Figure 2: Response surface plot for particle size and drug content.

\section{DISCUSSION}

Aripiprazole is atypical antipsychotic drug, exhibits very low aqueous solubility and high lipophilicity and thus classified as BCS Class IV drug. ${ }^{1-4}$ In present investigation, this poorly water soluble drug Aripiprazole is successful incorporated into micro-emulsion by Qbd approach. Based on solubility, oleic acid is selected as oil phase while Tween 80 and Transcutol - $p$ are selected as surfactants and co surfactants respectively for micro-emulsion formulation..$^{7-9}$ Pseudo ternary phase

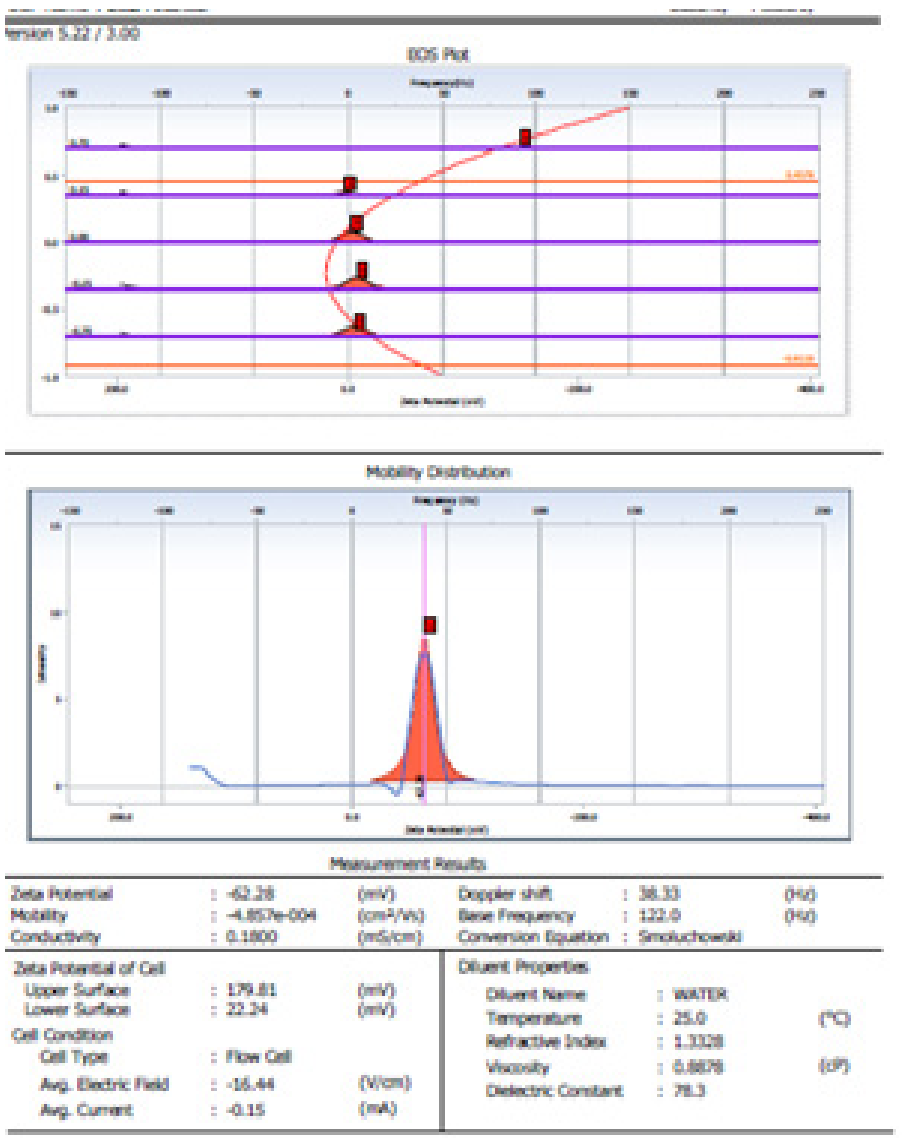

Figure 3: Particle size and Polydispersity index (PDI) of batch F9.

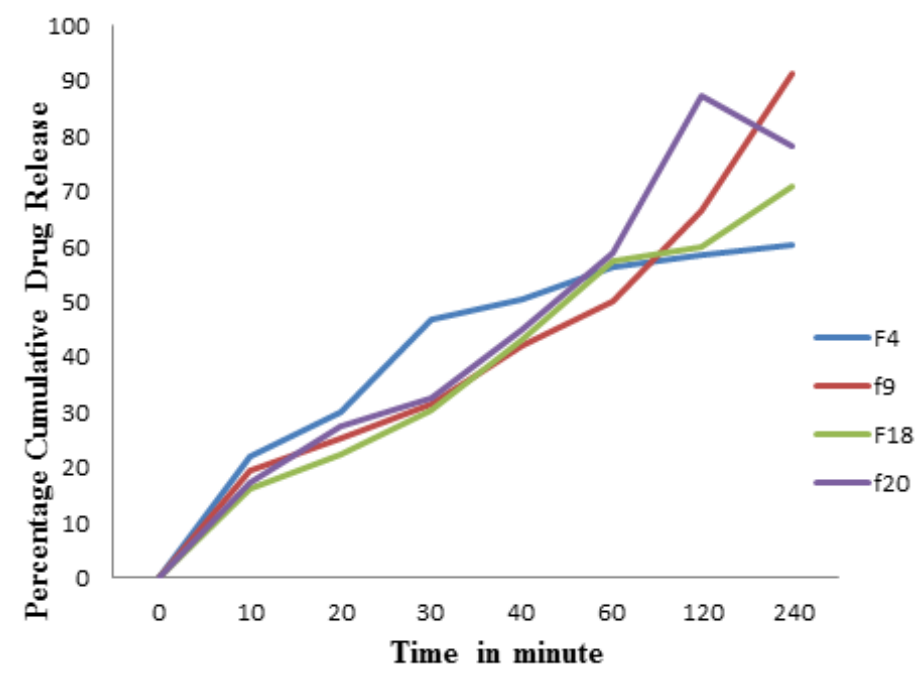

Figure 4: Percentage drug release Vs time in min. 
Table 3: Quality Target Product Profile (QTPP) and Critical Quality Attributes (CQAs) of AME.

\begin{tabular}{|c|c|c|c|c|c|}
\hline \multicolumn{6}{|c|}{ 3-A: Quality Target Product Profile (QTPP) with their justification } \\
\hline QTPP Elements & \multicolumn{3}{|c|}{ Target } & \multicolumn{2}{|c|}{ Justification } \\
\hline Dosage form & \multicolumn{3}{|c|}{ Microemulsion } & $\begin{array}{r}\text { Selection of } A \\
\text { helps in th }\end{array}$ & $\begin{array}{l}\text { le Micro emulsion } \\
\text { delivery system }\end{array}$ \\
\hline Dosage type & \multicolumn{3}{|c|}{ Rapid release } & Faster release leadi & Inced therapeutic effects \\
\hline Dosage strength & \multicolumn{3}{|c|}{$15 \mathrm{mg}$} & Incorporated $\mathrm{i}$ & formulation of ME \\
\hline Route of Administration & \multicolumn{3}{|c|}{ Nasal } & Goo & atic effect \\
\hline Stability Storage & \multicolumn{3}{|c|}{ At least 6 months at various storage temperatures } & To maintain therap & ntial of the drug during \\
\hline \multicolumn{6}{|c|}{ 3-B: Critical Quality Attributes (CQAs) with their justification } \\
\hline Quality Attributes of the Drug Product & \multicolumn{2}{|c|}{ Target } & Is this a CQA? & \multicolumn{2}{|c|}{ Justification } \\
\hline $\begin{array}{l}\text { Physical attributes } \\
\text { Color }\end{array}$ & & & No & \multicolumn{2}{|c|}{$\begin{array}{l}\text { Physical attributes of the formulation were not } \\
\text { considered }\end{array}$} \\
\hline $\begin{array}{c}\text { Odor } \\
\text { Appearance }\end{array}$ & \multicolumn{2}{|c|}{ Unpleasant } & No & \multicolumn{2}{|c|}{$\begin{array}{l}\text { order as these are not directly linked to efficacy and } \\
\text { safety }\end{array}$} \\
\hline Globule size & Less & $0 \mathrm{~nm}$ & Yes & $\begin{array}{r}\text { Smaller globule s } \\
\text { hence }\end{array}$ & $\begin{array}{l}\text { will permeation drugs } \\
\text { ed as critical }\end{array}$ \\
\hline Percentage of non-ionic surfactant & Higher an & $\begin{array}{l}\text { ut not cause } \\
\text { ect }\end{array}$ & Yes & Higher amount of & which low the particle \\
\hline \multicolumn{6}{|c|}{ 3-C: Critical Quality Attributes (CQAs) Analysis } \\
\hline Preprocess attribute & \multicolumn{3}{|c|}{ In process attribute } & \multicolumn{2}{|c|}{ Post process } \\
\hline Preformulation attributes & \multicolumn{3}{|c|}{ Magnetic stirrer equipment attributes } & & tributes \\
\hline Formulation attributes & \multicolumn{3}{|c|}{ Evaluation equipment attributes } & Storage & ity attributes \\
\hline \multicolumn{6}{|c|}{ 3-C.1: Pre-formulation and Formulation attributes } \\
\hline CQA Parameter & \multicolumn{2}{|c|}{ Oleic acid } & Tween 80 & Transcutol-p & AME Formulation \\
\hline 1.Physical parameter & \multicolumn{2}{|c|}{ Non- critical } & Non- critical & Non- critical & Critical \\
\hline 2.Solubility & & & Critical & Critical & Critical \\
\hline 3.Compatilbity study & & & Critical & Critical & Critical \\
\hline 4 Viscosity & & & Non- critical & Non- critical & Critical \\
\hline 5.Melting point & & & Non- critical & Non- critical & Non- critical \\
\hline & & 2: In process & quipment) Attributes & & \\
\hline CQA parameter & & & Equip & & \\
\hline & & tivn & & Evaluation equipr & \\
\hline & Mas & tirrer & UV Instrument & & \\
\hline & Time & Speed & Dilution & Time & Speed \\
\hline Particle size & Critical & Critical & Non- critical & Non- critical & Non- critical \\
\hline Physical appearance & Critical & Critical & Non- critical & Critical & Critical \\
\hline Drug content & Critical & Critical & Critical & Non- critical & Non- critical \\
\hline Drug diffusion & Critical & Critical & Non- critical & Critical & Critical \\
\hline & & 3.C-3: Post $\mathrm{F}$ & cess attributes & & \\
\hline CQA & Packa & tribute & Storage attribute & Stability attribut & \\
\hline Dosage form & Critical r & vith dosage & $\begin{array}{l}\text { Critical related with } \\
\text { dosage form }\end{array}$ & Critical $\mathrm{r}$ & dosage form \\
\hline Appearance & Critical re & $\begin{array}{l}\text { th different } \\
\text { ice }\end{array}$ & Not critical & Critical relate & ferent appearance \\
\hline Particle size & Critical rela & dosage form & $\begin{array}{l}\text { Critical related with } \\
\text { dosage form }\end{array}$ & Critical $\mathrm{r}$ & h dosage form \\
\hline Turbidity & & & Critical & & \\
\hline Drug release & & & Not critical & & \\
\hline
\end{tabular}


Table 4: Pharmaceutical Evaluation Results of AME.

\begin{tabular}{|c|c|c|c|}
\hline Sr. No & Parameter & Result & Inference \\
\hline 1 & Appearance & $\begin{array}{l}\text { All the formulation found clear and devoid of any } \\
\text { sign of precipitation }\end{array}$ & No sign of precipitation \\
\hline 2 & Refractive Index & In the range $1.40 \pm 0.53$ to $1.41 \pm 0.7637$ & Micro emulsion is transparent with low RI \\
\hline 3 & Viscosity & $110 \pm 2.51 \mathrm{cp}$ & Formulation is o/w type \\
\hline 4 & $\mathrm{pH}$ & between 5.5 and 6.5 & Similar to the normal $\mathrm{pH}$ ranges of nasal fluids \\
\hline 5 & Conductivity & $201(\mathrm{~ms} / \mathrm{cm})$ & Indicates water is in a contentious phase and ME to be of oil-in-water \\
\hline 6 & $\begin{array}{l}\text { Drug content } \\
\text { estimation }\end{array}$ & $\begin{array}{c}\text { Batches F7, F9, F15, F16, F17, F19, F20 shown \% } \\
\text { drug content } 90,90,90,98.33,90,95,95 \text { respectively } \\
\text { at } 255 \mathrm{~nm}\end{array}$ & Out of these 7 batches, F16 batch shown highest drug content \\
\hline 7 & Particle size & $\begin{array}{l}\text { AME F9 batch shown particle size } 95.2 \mathrm{~nm} \text { with } \\
\text { Polydispersity index } 0.543 \text { [Figure 3] }\end{array}$ & $\begin{array}{l}\text { PDI value } 0.5 \text { indicates particles of batch F9 are monodisperse, } \\
\text { desirable for micro emulsion formulation }\end{array}$ \\
\hline 8 & Zeta Potential & $\begin{array}{l}\text { BatchesF4,F9,F18,F22,F23 shown zeta potential } \\
-17.3,62.28,-18.1,-30.1,-32.8 \mathrm{mV} \text { respectively }\end{array}$ & $\begin{array}{l}\text { Zeta potential more than }-30 \text { shows most stability of formulation. F9 } \\
\text { batch shown }-62.28 \mathrm{mV} \text { zeta potential which is much higher than }-30 \\
\qquad \mathrm{mV} \text { as compared to other batches }\end{array}$ \\
\hline \multirow[t]{2}{*}{9.} & Stability study & & \\
\hline & $\begin{array}{l}\text { Type of Stability } \\
\text { Study }\end{array}$ & Observation & Inference \\
\hline a. & Physical Stability & $\begin{array}{c}\text { No phase separation observed after application of } \\
\text { temperature cycle }\end{array}$ & Pass the test \\
\hline b. & Chemical stability & $\begin{array}{l}\text { At room temperature, globule size was slightly } \\
\text { increased but drug content remained unchanged }\end{array}$ & Pass the test \\
\hline c. & $\begin{array}{l}\text { Thermodynamic } \\
\text { study }\end{array}$ & $\begin{array}{l}\text { No significant changes observed at different } \\
\text { temperature ranges, Freeze thaw cycle } \\
\text { Centrifugation }\end{array}$ & Pass the test \\
\hline
\end{tabular}

diagram of 1:2 ratio of surfactant and co-surfactant showed stable micro emulsion region and hence same ratio used further. ${ }^{9-10}$

Second-order quadratic polynomial equation and contour plots are constructed by using multiple regression analysis. Microemulsion system optimized using Design space (overlay plot) with softwaresuggested levels of independent variables that could be transformed to desired responses. ${ }^{10-12}$

From response model equations $(1,2)$ it is observed that, variables $\mathrm{X} 1$, Oleic acid have negative effect on Particle size while variable X4, distilled water shows negative effect on drug content. Particle size of Aripiprazole is inversely proportional to drug concentration in oleic acid while drug content percentage is inversely proportional to amount of distilled water in micro emulsion. Table 1 is elaborating observed responses of particle size and percentage drug content for all 29 batched obtained from Box Behnken Design application. Table 4 has summarised Analysis of variance (ANOVA) results for Particle Size (R1) and Drug Content (R2). In case of response factor R1 i.e. particle size, the Predicted R-Square value, 0.1085 was in reasonable agreement with the Adjusted $\mathrm{R}$-Squared of 0.3040 . Adequate precision measures the signal to noise ratio. Adequate precision value for this response factor was 9.531which indicates an adequate signal. While for response factor R2, The Predicted R-Square value, 0.1085 was in reasonable agreement with the Adjusted R-Square value 0.3040 and adequate precision was in desirable range i.e. 5.395 which are desirable for quadratic shape of model. Data from ANOVA Table 2 also indicated effects of individual and interaction variables on Microemulsion formulation. The model $F$ values of responses, 5.04 and 2.68 indicates models are significant. ${ }^{10,11} P$ values of both responses were found to be within 0.05 ranges which also imply models are significant. ${ }^{12,13}$ Based on the experimental design, the factor combination resulted in different particle size. Particle size of micro emulsion produced by water titration showed least increase in size.
The preliminary step of the product development based on the QbD approach is the description of the quality target product profile (QTPP), which is evaluated for various parameters like dosage form, type, strength, route of administration, stability. ${ }^{12,13}$

QTPP and CQA revealed formulation is desirable and safe. Similarly physical attributes like color, odor, appearance, globule size, \% non-ionic surfactant are also evaluated and it is found that role of globule size and percentage non-ionic surfactant are two critical quality attributes in development of Aripiprazole microemulsion. ${ }^{11}$ Storage and Pre-process attribute (Preformulation and Formulation attributes), in process attribute (Magnetic stirrer and evaluation equipment attributes) and post process attributes (Packaging, Storage and stability) are evaluated and results are summarised in Table $4 .{ }^{12}$ Solubility and compatibility with excipients are critical attributes in pre-formulation.

This highlights the importance of rigorous quality control analyses early in the development of microemulsion of Aripiprazole. Risk analysis narrowed down the number of process parameters that were studied and the use of DoE further saved time by minimizing the number of runs that were needed to understand that relationship between the process parameters and the CQAs.

Finally the optimised formulation of the F9 consisting of oleic acid, tween 80 , transcutol-p and water is found transparent, clear, less viscous $(120 \mathrm{cp}$ ) having particle size $95.2 \mathrm{~nm}, \mathrm{pH} 6.0$, drug content $90 \%$ and nasal permeability release about $87.33 \%$ within $4 \mathrm{hr}$. Refractive index and \% transmittance showed good isotropic formulation. The stability studies confirmed that AME optimized batch is stable for 3 months.

In vitro studies on sheep mucosa revealed overall increase in bioavailability of the drug by nasal administration in the form of microemulsion. The experimental findings collectively support potential of 
micro-emulsion in enhancement of nasal absorption and bioavailability of poorly water soluble Aripiprazole.

\section{CONCLUSION}

Thus, it can be concluded that ARP having poor solubility can be formulated as micro emulsion, which increase the solubility of the drug and hence, which will increase bioavailability than other dosage form. However, this research work must be further continued to prove its efficacy and safety through pre-clinical and clinical evaluation.

\section{CONFLICT OF INTEREST}

The authors declare no conflict of interest

\section{ABBREVIATIONS}

BCS: Biopharmaceutical classification system; ME: Microemulsion; QTPPL: Quality Target Product Profile; QbD: Quality by design; CQA: Critical Quality Attributes; ICH: International conference on hormanization; QRM: Quality Risk Management; CPP: Critical process parameter; DOE: Design of Experiment; PIT: Phase inversion method; ARP: Aripiprazole; Smix: Ratio of oil surfactant and co-surfactant; PDI: Polydisperbility index; ANOVA: Analysis of variance: 34: Three level and four factor.

\section{REFERENCES}

1. Ehret MJ, Davis E, Luttrell SE, Clark C. Aripiprazole Lauroxil NanoCrystal® Dispersion Technology (Aristada Initio@). Clin Schizophr Relat Psychoses. 2018;12(2):92-6.

2. Hard ML, Wehr AY, Sadler BM, Mills RJ, Moltke LV. Population Pharmacokinetic Analysis and Model-Based Simulations of Aripiprazole for a 1-Day Initiation Regimen for the Long-Acting Antipsychotic Aripiprazole Lauroxil. Eur J Drug Metab Pharmacokinet. 2018;43(4):461-469

3. Al-Dhubiab BE. Aripiprazole Nanocrystal Impregnated Buccoadhesive Films for
Schizophrenia. J Nanosci Nanotechnol. 2017;17(4):2345-52.

4. Jacob S, Nair AB, Shah J. Emerging role of nanosuspensions in drug delivery systems. Biomater Res. 2020;24(1):3.

5. Pathak R, Dash RP, Misra M, Nivsarkar M. Role of mucoadhesive polymers in enhancing delivery of nimodipine microemulsion to brain via intranasal route. Acta Pharm Sin B. 2014;4(2):151-60.

6. Yu LX, Amidon G, Khan MA, et al. Understanding pharmaceutical quality by design. AAPS J. 2014;16(4):771-83.

7. Mishra V, Thakur S, Patil A, Shukla A. Quality by design $(\mathrm{QbD})$ approaches in current pharmaceutical set-up. Expert Opin Drug Deliv. 2018;15(8):737-58.

8. Moghimipour E, Salimi A, Karami M, Isazadeh S. Preparation and characterization of dexamethasone microemulsion based on pseudoternary phase diagram. Jundishapur J Nat Pharm Prod. 2013;8(3):105-12.

9. Pessoa RS, França EL, Ribeiro EB, et al. Microemulsion of babassu oil as a natural product to improve human immune system function. Drug Des Devel Ther. 2014;9:21-31.

10. Palagati S, Sv S, Kesavan BR. Application of computational tools for the designing of Oleuropein loaded nanostructured lipid carrier for brain targeting through nasal route. Daru. 2019;27(2):695-708.

11. Politis SN, Colombo P, Colombo G, M Rekkas D. Design of experiments (DoE) in pharmaceutical development. Drug Dev Ind Pharm. 2017;43(6):889-901.

12. Pallagi $E$, Jójárt-Laczkovich $O$, Németh Z, Szabó-Révész P, Csóka I. Application of the QbD-based approach in the early development of liposomes for nasal administration. Int J Pharm. 2019;562:11-22.

13. Rahman Z, Xu X, Katragadda U, Krishnaiah YS, Yu L, Khan MA. Quality by design approach for understanding the critical quality attributes of cyclosporine ophthalmic emulsion. Mol Pharm. 2014;11(3):787-99.

14. Cao Y, Gao H, Xia H, et al. Development and Evaluation of a Water-in-oil Microemulsion Formulation for the Transdermal Drug Delivery of Teriflunomide (A771726). Chem Pharm Bull. 2019;67(8):786-94.

15. Negi P, Singh B, Sharma G, Beg S, Raza K, Katare OP. Phospholipid microemulsion-based hydrogel for enhanced topical delivery of lidocaine and prilocaine: QbD-based development and evaluation. Drug Deliv. 2016;23(3):951-67.

16. Shah V, Sharma M, Pandya R, et al. Quality by Design approach for an in situ gelling microemulsion of Lorazepam via intranasal route. Mater Sci Eng C Mater Biol Appl. 2017;75:1231-41.

17. Vitorino C, Silva S, Gouveia F, Bicker J, Falcão A, Fortuna A. QbD-driven development of intranasal lipid nanoparticles for depression treatment. Eur J Pharm Biopharm. 2020;153:106-20

Article History: Submission Date : 25-04-2020; Revised Date : 15-08-2020; Acceptance Date : 10-09-2020.

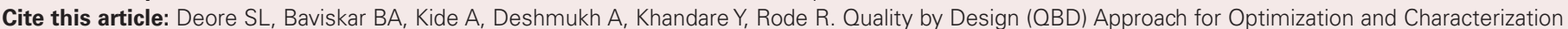
of Micro emulsion based Nasal formulation of Antipsychotic/Antischizophrenic Drug- Aripiprazole. Int. J. Pharm. Investigation, 2020;10(3):286-93 